\title{
How Economic Inequality Shapes Mobility \\ Expectations and Behavior in Disadvantaged Youth
}

\author{
Alexander S. Browman ${ }^{\mathrm{a}}$ \\ Mesmin Destin ${ }^{\mathrm{b}, \mathrm{c}, \mathrm{d}}$ \\ Melissa S. Kearney ${ }^{\mathrm{e}, \mathrm{g}}$ \\ Phillip B. Levinef,g
}

\author{
${ }^{a}$ Lynch School of Education, Boston College, Chestnut Hill, MA 02467 \\ ${ }^{\mathrm{b}}$ School of Education and Social Policy, Northwestern University, Evanston, IL 60208 \\ ${ }^{c}$ Department of Psychology, Northwestern University, Evanston, IL 60208 \\ ${ }^{\mathrm{d}}$ Institute for Policy Research, Northwestern University, Evanston, IL 60208 \\ e Department of Economics, University of Maryland, College Park, MD 20742 \\ ${ }^{\mathrm{f}}$ Department of Economics, Wellesley College, Wellesley, MA 02481 \\ g National Bureau of Economic Research, Cambridge, MA 02138
}

Nature Human Behaviour, 2019

(C) Springer Nature Limited, 2019. This paper is not the copy of record and may not exactly replicate the authoritative document published in Nature Human Behaviour.

The final article is available at: https://doi.org/10.1038/s41562-018-0523-0 


\begin{abstract}
Economic inequality can have a range of negative consequences for those in younger generations, particularly for those from lower-socioeconomic status (SES) backgrounds. Economists and psychologists, among other social scientists, have addressed this issue, but have proceeded largely in parallel. This Perspective outlines how these disciplines have proposed and provided empirical support for complementary theoretical models. Specifically, both disciplines emphasize that inequality weakens people's belief in socioeconomic opportunity, thereby reducing the likelihood that low-SES young people will engage in behaviors that would improve their chances of upward mobility (e.g., persisting in school, averting teenage pregnancy). In integrating the methods and techniques of economics and psychology, we offer a cohesive framework for considering this issue. When viewed as a whole, the interdisciplinary body of evidence presents a more complete and compelling framework than does either discipline alone. We use this unification to offer policy recommendations that would advance prospects for mobility among low-SES young people.
\end{abstract}




\section{How Economic Inequality Shapes Mobility}

\section{Expectations and Behavior in Disadvantaged Youth}

High and rising economic inequality in the United States ${ }^{1-3}$ has led to widespread concern about the consequences for the promise of opportunity and mobility for those in younger generations. Scholars across social science disciplines have considered how exposure to high levels of economic inequality affects the attitudes and behaviors of youth and young adults, especially among those from low-socioeconomic status (SES) backgrounds. In this Perspective, we focus on research from the fields of economics and psychology on this issue, which have proceeded largely in parallel but unwittingly proposed and provided empirical support for a common notion: namely, that economic inequality weakens people's belief in socioeconomic opportunity, thereby affecting the likelihood that youth from low-SES backgrounds will engage in behaviors associated with socioeconomic success.

The purpose of this Perspective is to outline and integrate the complementary theoretical frameworks and empirical findings that have emerged across economics and psychology to offer a cohesive framework for considering how economic inequality shapes the expected and realized life opportunities of youth and young adults from low-SES backgrounds. We review models and empirical work across disciplines and unify the models and terminology. Our goal is to demonstrate that the interdisciplinary body of evidence presents a more complete and compelling framework for our understanding of the issue than does either discipline alone. We conclude with observations for public policy that would help improve the lives of low-SES young people based on what we have learned.

\section{Unified Framework}

Figure 1 presents our unified theoretical model that merges the perspectives of economists and psychologists regarding an important pathway by which economic inequality 
influences the behavior of young people from low-SES backgrounds. The framework begins with the level of economic inequality that exists in the environment facing these individuals (Box A). This factor is proposed to have a negative relationship with their beliefs regarding socioeconomic mobility (Box B) - that is, the tendencies to view society as a place where socioeconomic opportunities and mobility are both attainable and within one's control. Specifically, economic inequality in a society is proposed to weaken all inhabitants' beliefs regarding the attainability of socioeconomic success and upward mobility, in addition to its potential negative effects on access to important material resources and opportunities ${ }^{4}$. Those weakened beliefs are then hypothesized to lead to a decreased likelihood that low-SES young people will engage in behaviors associated with socioeconomic success (Box C), such as persisting in school, averting teenage pregnancy, and avoiding illegal and delinquent behavior. In sum, our unified model proposes that exposure to economic inequality can contribute to concrete negative outcomes for young people from low-SES backgrounds by weakening the motivating belief that achieving socioeconomic success is possible for them. We offer this as one important channel, without ruling out the very real possibility of other potential channels through which higher levels of economic inequality exacerbate economic disparities and hinder upward mobility of those from lower SES backgrounds. In addition, numerous other structural and contextual factors may also contribute to differences in people's beliefs about mobility and opportunity $^{5}$. In our framework, we focus on economic inequality as a key contextual factor because we are building directly on theoretical and empirical innovations in both economics and psychology that focus on economic inequality, demonstrating how mutual consideration of similar ideas provides a compelling framework for understanding this issue. 
Box A

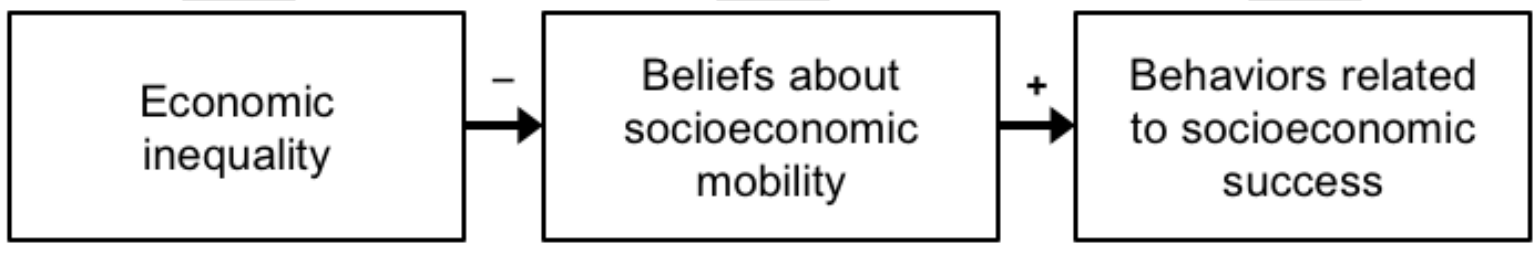

Figure 1. Unified theoretical framework. This figure demonstrates our conceptual model, in which increased economic inequality in a society weakens inhabitants' beliefs about the attainability of socioeconomic mobility, which positively predict engagement in behaviors related to socioeconomic success among youth from low-SES backgrounds.

\section{Conceptual Perspectives}

\section{Anthropology and Sociology}

Much of the early interest in the relationships between economic inequality and people's beliefs and behaviors emerged in the fields of cultural anthropology and sociology, in response to the controversial "culture of poverty" theory". This perspective proposed that low-SES youth often remained in poverty as adults not only because of a lack of resources and opportunities, but also because of how these tangible disparities affect "the worldview, aspirations, and character of the children who grow up in it" (p. 199). Specifically, culture of poverty theorists ${ }^{6}$ have argued that those who grow up in a "marginal position" come to internalize "feelings of hopelessness and despair that develop from the realization of the improbability of achieving success" which results in them being "psychologically unready to take full advantage of changing conditions of improving opportunities that may develop in their lifetime” (p. 189-90).

In this Perspective, we emphasize the role of structural factors over person-specific factors, while still maintaining an important role of internal psychological factors, like "feelings of hopelessness and despair," in driving behavior among low-SES youth. In his seminal book The Truly Disadvantaged ${ }^{7}$, the prominent sociologist William Julius Wilson argued that poverty among African-Americans living in economically disadvantaged communities was primarily 
maintained by a specific subtype of economic inequality: "A social isolation that excludes them from the job network system that permeates other neighborhoods and that is so important in learning about or being recommended for jobs that become available in various parts of the city" (p. 57). As he elaborates in When Work Disappears ${ }^{8}$, "In [low-SES] communities [marked by structural inequalities like these] where the young people have little reason to believe that they have a promising future - including the prospects of stable employment... adolescents and young adults are more likely to engage in behaviors that jeopardizes their chances for social and economic mobility" (p. 107). In contrast with the original culture of poverty theory, such perspectives suggest that structural changes (e.g., reducing the job-based inequalities that exist between lower- and higher-SES neighborhoods) would have palatable influences on the expectations and behaviors of low-SES youth and young adults. The psychological and economic perspectives that are relevant to the present framework have emerged from a similar structurally-focused perspective.

\section{Social Psychology}

Numerous social psychological theories contend that individuals are motivated to persist longer on difficult tasks and domains that feel connected to the possibility of reaching the positive and successful futures that they envision for themselves ${ }^{9-13}$. This relationship is especially important among youth and young adults—individuals who stand on the bridge between their backgrounds of origins and various potential futures. For example, students who see a connection between academics and the kinds of jobs they desire to have in the future are more motivated to work hard in school and ultimately have better academic outcomes than those who do not naturally see these connections ${ }^{14}$. Similarly, young adults who naturally see a strong connection between their current lives and actions and the person they will become in the future 
make more long-term focused financial decisions ${ }^{15}$ and are less likely to engage in delinquent and illegal behaviors than those who do not naturally see these connections ${ }^{16-18}$.

However, at the heart of social psychology (and in line with contemporary perspectives advanced by cultural sociologists and anthropologists, discussed above) is a focus on the role of contextual and environmental factors in shaping people's beliefs and expectations ${ }^{13,19}$. Social psychological perspectives suggest that the extent to which a task or domain feels connected to the futures that youth and young adults desire for themselves is dynamic, meaning that it shifts from moment to moment depending upon cues available in the salient context ${ }^{10,20,21}$. For instance $^{22}$, because low-SES youth come from backgrounds that are structurally characterized by restricted access to economic capital and power, they are likely to be socialized to be interdependent — to adjust to the social context, and to be aware of their position in the social hierarchy and avoid standing out. Research has shown that these tendencies are motivationally and behaviorally adaptive in some settings, specifically certain home environments. At the same time, these tendencies are also sharply mismatched and motivationally detrimental in settings like traditional Western schools and workplaces. This is because those settings promote and favor different, more independence-focused tendencies, like acting to influence one's social contexts and working to stand out from others. In other words, the extent to which characteristics of an environment support or conflict with youth's own deeply-held characteristics—such as their tendencies, worldviews, or aspirations — can shape their motivation to engage in behaviors in those environments.

The unified framework we highlight proposes that one contextual cue that can influence individuals' behavior on tasks and in domains that could contribute to desired future outcomes is the level of economic inequality in society. Across many developed countries, a majority of people express a strong desire to improve their socioeconomic standing and associated quality of 
life ${ }^{23,24}$. This drive is especially pronounced among young people who come from low-SES backgrounds - those who stand to gain the most from attaining some degree of upward mobility ${ }^{25}$.

Over the past several decades, however, as economic inequality has risen, absolute income mobility in the U.S. has declined, meaning that it is less likely for the current generation to have higher incomes than their parents, as compared to earlier generations ${ }^{26}$. Furthermore, increasing levels of economic inequality typically generate increased tangible disparities in lower- and higher-SES individuals' ability to access resources and opportunities that contribute to success and well-being in life (school funding, social services, safe neighborhoods, political influence, etc. $)^{27-33}$. For example, as economic inequality has risen, college graduation rates among high SES students have pulled further ahead of their low-SES peers ${ }^{34}$, especially at schools that have historically produced high mobility rates among its low-SES graduates ${ }^{35}$. Living in areas with high levels of economic inequality may therefore signal to inhabitants that people in that society are unlikely to be able change their position on the socioeconomic ladder. And if they have reason to believe that mobility generally cannot occur, behaviors related to socioeconomic success (e.g., persisting in school, avoiding deleterious behaviors) may feel pointless for people at the bottom of the SES distribution, and their motivation to engage in them may therefore wane.

\section{Economics}

Economic models of behavior and social outcomes in the neoclassical framework have traditionally not incorporated notions of culture or expectations. Instead, the standard economics approach generally models decision-making as a rational, fully-informed consideration of the benefits and costs associated with various options. Individuals are therefore presumed to make the decision that yields the best outcome for them given the relevant constraints that they face. 
The "human capital model" in labor economics ${ }^{36-38}$ posits that because economic inequality implies an increase in the returns to investment, when inequality is higher, individuals (especially those from low-SES backgrounds, who stand to gain the most) should be more likely to make human capital investments like attaining higher levels of education.

An important element of these traditional models is that there is not an explicit consideration of how social or cultural forces might affect the subjective probability of success held by the decision-maker. Recent work incorporates this more nuanced perspective about how context-driven subjective perceptions might influence decision making among low-SES individuals in particular. One such framework, the "economic despair" model ${ }^{39,40}$, posits that greater inequality leads low-SES youth to perceive a lower rate of conditional success for themselves, thereby offsetting any potential "aspirational" effect of higher investment premiums. But crucially, the same level of inequality might cause some individuals to invest more in their future, while discouraging others; both can occur at the same time. The main contribution of the economic despair model is thus the recognition that decision-makers differ in their anticipated personal probability of success conditional on investment, either because of how contextual factors shape their actual or perceived differences in returns to investment. Those with a lower anticipated success probability have lower perceived returns, and are thus less likely to take actions that would lead to economic or social success, like staying in school ${ }^{39}$ or avoiding childbearing at a young age ${ }^{40}$.

A related model provides a theory of "socially determined aspirations"41. This framework mathematically models the interaction of economic inequality with aspirations and ultimately economic growth: economy-wide outcomes determine individual-level aspirations, which in turn determine investment incentives and therefore economic growth. This model makes explicit the notion that "individuals do not choose their level of aspirations. It is determined by their 
experience and the income distribution around them" (p. 491)." This is a novel contribution beyond previous work that has highlighted the important role of aspirations themselves in driving outcomes ${ }^{42}$. A central feature of the model that drives the main results is that aspirations which are moderately above an individual's current standard of living tend to encourage investment, while still higher aspirations may lead to frustration.

A distinct but related line of inquiry into "identity economics"43 incorporates the appropriateness of one's behavior relative to others in an individual's relevant social category into a more traditional economic model of the decision-making process. One category explicitly considered in this work is the economics of social exclusion and poverty. Because individuals identify themselves with the members of their social group, another individual's attempt to leave that social group can sometimes be perceived as threatening. The authors of this work note that "those who seek upward mobility are often teased by their peers" (p. 725). This type of model relates to our conceptual framework captured in Figure 1 because young people who grow up in a more unequal society might have a stronger sense of where they are in the social and economic hierarchy, making such identities more salient. This could reduce the likelihood that young people undertake actions that would advance their own upward mobility.

\section{Empirical Evidence}

Complementary empirical work across disciplines has also emerged that supports the relationship between economic inequality, people's beliefs about socioeconomic mobility, and behaviors related to socioeconomic success among young people from low-SES backgrounds. The research methods and large-scale datasets employed by economists are well-suited to capture broad, objective, societal-level indicators and their relationship to individual behavior in the aggregate. Economists therefore tend to measure well the link between Box A and Box C in Figure 1, without being able to directly test the intermediate step at Box B. Social psychologists, 
on the other hand, are adept at designing smaller scale, controlled experiments that investigate people's subjective internal experiences, which can therefore provide compelling evidence for the mediating role of people's perceptions of socioeconomic mobility in this model (Box B). Taken together, the complementary strengths of the empirical practices employed by the two disciplines provide a strong, unified body of evidence in favor of this unified framework.

\section{Inequality Reduces Behaviors Related to Economic Success}

Empirical work conducted by economists focusing on the economic despair model have examined the relationship between inequality and two specific teen behaviors: completing high school $^{39}$ and avoiding a non-marital birth at a young age ${ }^{40}$. These studies use nationallyrepresentative data from the National Surveys of Family Growth (for young, non-marital childbearing) and from the National Longitudinal Surveys of Youth (1979 and 1997 cohorts), the National Educational Longitudinal Survey, the High School and Beyond survey, and the Educational Longitudinal Survey (for high school dropout). These data sources provide researchers with objective information on tens of thousands of American teenagers, including residential information (available as restricted use data files for approved projects) and individual-level demographics that allows the researchers to calculate measures of local income inequality, youth's SES backgrounds (based on maternal education levels ${ }^{44}$ ), and potential alternative contributors that are important to account for (e.g., race, whether there are two parents in the home, local economic and policy conditions).

These analyses find a negative relationship between state and metro area measures of inequality and behaviors related to socioeconomic success among low-SES youth. As shown in Figure 2, 25 percent of boys who come from lower-SES backgrounds (i.e., those with a mother who dropped out of high school) and who lived in the most unequal states dropped out of high

school, compared to 19 percent of boys in the least unequal states ${ }^{39}$. That gap across states does 
not emerge among higher-SES students (i.e., those whose mothers are more highly educated).

Furthermore, that six percent gap in dropout rates between low-SES boys in states with higher and lower levels of inequality remains in an econometric model that controls for demographics, labor market conditions, and relevant public policies. Similarly, analyses of data on marriage and childbearing reveal that low-SES girls are about 5 percentage points more likely to become young unmarried mothers if they grow up in a more unequal state as compared to low-SES girls in more equal states ${ }^{40}$.

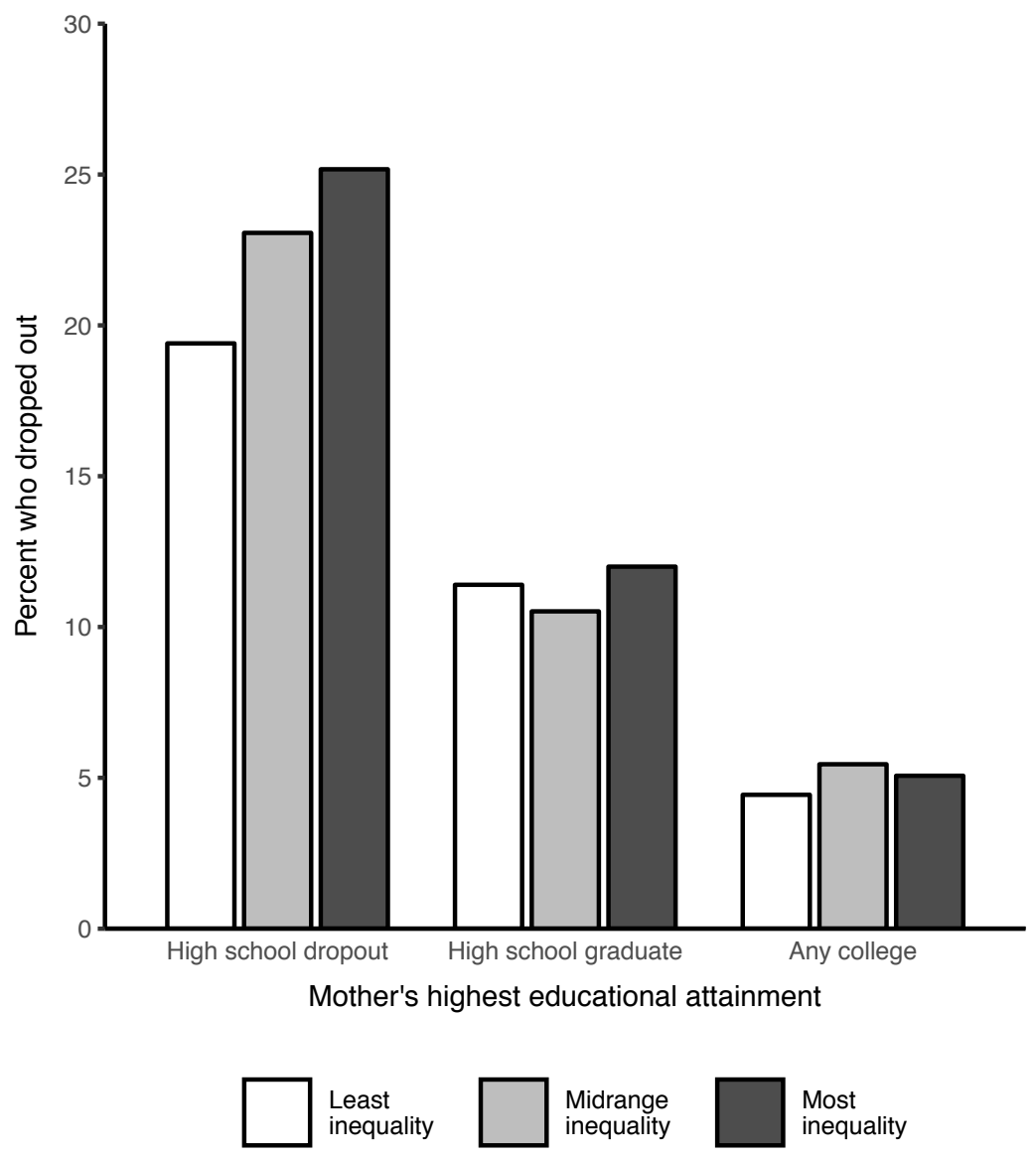

Figure 2. Inequality, maternal education, and high school dropout rates for boys. This figure depicts high school dropout rates for boys, distinguished by the level of income inequality at the state level, measured as the 50/10 ratio, and their mothers' highest level of educational attainment (high school dropout, high school graduate, or any college) as an index of SES. These data represent 25,816 boys from five national datasets (1979 and 1997 National Longitudinal Surveys of Youth, National Educational Longitudinal Survey, High School and Beyond, and Educational Longitudinal Survey). State level income data used to create the 50/10 ratio were obtained from the U.S. Census Bureau. Figure adapted with permission from ref. 39, Brookings. 
To determine that the observed relationship between income inequality and individual level outcomes is due to income inequality and not some other correlated, confounding factor, the authors estimate a series of "horse race" models. These regression models include interaction terms between other factors that might be correlated with aggregate levels of income inequality and exert their own effect on the outcomes of low-SES youth, like the industrial composition of the labor market, the demographic characteristics of a state, measures of residential segregation, measures of public school financing, and other features of the income distribution. In all cases, the addition of these additional interaction terms to the regression model has no bearing on the estimated effect of inequality on the outcomes of low-SES youth. The robustness of the main findings with regard to high school completion rates and rates of early non-marital childbearing across specifications bolsters the case for a causal interpretation of the relationship between economic inequality itself (as opposed to as a proxy for something else) and these outcomes. These studies thus provide compelling support for the hypothesis that greater income inequality influences low-SES youth's behaviors related to socioeconomic success.

\section{Inequality Weakens Beliefs about Economic Mobility}

Empirical research in psychology has addressed whether economic inequality influences behavioral engagement among low-SES young people specifically by weakening people's beliefs regarding the attainability of socioeconomic mobility. Lab and real-world experiments that can causally test the antecedents and consequences of people's subjective, internal experiences are common in social psychological research ${ }^{19,45}$. In such designs, participants are randomly assigned to distinct experimental groups, such that some groups (but not others) are exposed to actual environmental conditions (e.g., the unequal distribution of resources in an economic game ${ }^{46,47}$ ) or biased information about the social environment that they inhabit (e.g., a newspaper article discussing the lack of intergenerational mobility in a participant's country ${ }^{48-50}$ ). By only 
manipulating one factor of interest (e.g., the levels of economic inequality or socioeconomic mobility that one perceived in their society), these experimental designs provide controlled tests of whether these isolated factors have a causal influence on an outcome of interest.

A number of laboratory experiments from the social psychology literature provide causal evidence that heightened perceptions of economic inequality in a society can weaken beliefs about whether upward mobility is plausible among those living in those societies. One body of work involved experimentally manipulating participants' perceptions of economic inequality in their society by randomly assigning some participants (but not others) to read articles about rising inequality in their society ${ }^{51}$. Participants who were led to believe that the level of economic inequality in their society was high and rising believed that "getting ahead" in society depended more on uncontrollable structural factors (e.g., "coming from a wealthy family," "having well-educated parents") and less on controllable individual factors (e.g., "hard work," "ambition"). In other words, these participants were more skeptical about the extent to which the prospect of upward mobility in their society was within their control.

There is also direct evidence that heightened perceptions of inequality can lead people to become more skeptical about the prospect of socioeconomic mobility writ large. In a series of studies $^{52}$, participants' perceptions of economic inequality were experimentally manipulated by having them view a pie chart that ostensibly depicted the proportion of wealth owned by each quin- tile of the population in their current state of residence as being either highly unequal (poorest quintile: $1 \%$; second quintile: $3 \%$; middle quintile: $4 \%$; fourth quintile: $11 \%$; richest quintile: $81 \%$ ) or relatively more equal $(11 \%, 15 \%, 18 \%, 21 \% \text {, and } 35 \%)^{53}$. All participants then reported the extent to which they believed that people born into the poorest wealth quintile in the country would end up in a higher quintile as adults - that is, that they would experience upward mobility ${ }^{54}$. Results indicated that participants cued to view their society as highly unequal were 
less likely to believe that upward mobility could occur than those cued to view their society as relatively more equal. Additional research employing similar methodologies provides complementary findings with regard to people's perceptions of the likelihood that middle-SES individuals can experience upward mobility and that high-SES individuals can experience downward mobility (Browman \& Destin, manuscript in preparation). And across these numerous separate investigations ${ }^{51,52}$ (Browman \& Destin, manuscript in preparation), the effects of inequality on perceptions of mobility appear to emerge regardless of respondents' own SES. Together, then, these studies provide compelling causal support for the notion that societal- level economic inequality can negatively influence people's perceptions of whether socioeconomic mobility is generally attainable in their society.

\section{Mobility Beliefs Drive Behaviors Related to Economic Success}

Experimental studies have also provided causal evidence linking beliefs about socioeconomic mobility to behaviors related to socioeconomic success. These studies have involved experimentally manipulating low-SES young people's beliefs about the attainability of economic mobility in their society and examining its impact on behaviors relevant to achieving future socioeconomic success. In one lab experiment with university students and one field experiment with students at the critical middle school-to-high school transition ${ }^{48}$, students from lower- and higher-SES backgrounds were presented with information that either suggested that socioeconomic mobility was something that generally could or could not occur in their society. For example, at the beginning of the academic year, students in the field study were presented with a figure adapted from a report on socioeconomic mobility that depicted their country as currently having either a very low level of socioeconomic mobility or a much greater level. In both studies, lower (but not higher) SES students (based on household income) who were led to believe that economic mobility was more likely to occur demonstrated (on both self-report 
measures and behavioral academic tasks) greater inclinations to persist when faced with academic difficulty than those led to believe that mobility was less likely to occur. These results are displayed in Figure 3. And most critically, in the field study, this increased persistence among lower-SES students who were led to hold stronger mobility beliefs at the beginning of the academic year contributed positively to their official grades at the end of the academic year.
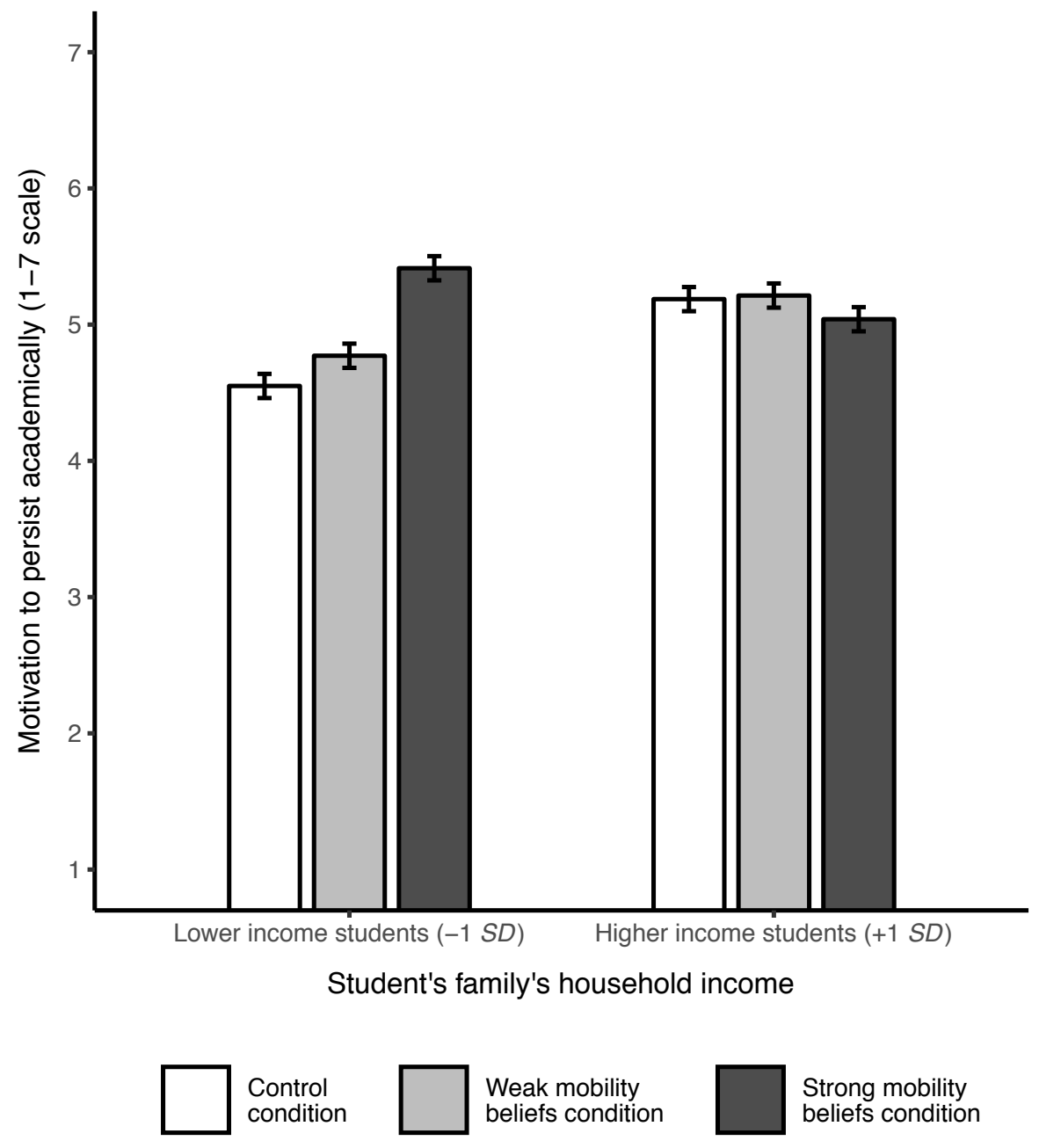

Figure 3. Motivation to persist academically by mobility beliefs and SES. This figure depicts high school students' $(N=170)$ self-reported motivation to persist when facing academic difficulty, separated by experimental condition and student's family household income. Students in the "weak" and "strong mobility salient" conditions were presented with figures that depicted mobility as either rare or common in their country before responding. Those in the control condition were not presented with a mobility manipulation before responding. Household income represents families' census block group's median income (obtained from the U.S. Census Bureau) and is plotted at $\pm 1 S D$. Error bars represent $\pm 1 S E$. Figure adapted with permission from ref. 48, Elvesier. 
Additional experimental investigations have provided further support for these relationships ${ }^{49,55}$. In one set of studies ${ }^{55}$, researchers recruited samples of university students from disadvantaged backgrounds (i.e., ethnic-minority group members) and manipulated the extent to which they viewed their society as a just and meritocratic place-one in which people's efforts are fairly rewarded. In one study, half of students were randomly assigned to read an article, ostensibly taken from a major newspaper, describing how "it is becoming more and more likely that the hard work of [university location] citizens will translate into occupational success, and less likely that factors such as gender or family connections will have an influence" (p. 157). Participants in the control condition read an article that also had a positive and optimistic message, but was not related to societal fairness. All participants then completed a measure of their interest in completing the years of schooling typically required to practice a series of desirable professions (e.g., lawyer). The researchers found that participants were more willing to complete additional years of schooling when they were led to believe that their society was becoming a more fair and meritocratic place, relative to participants in a control condition. In line with our unified framework, these researchers ${ }^{55}$ suggest that low-SES individuals might "calibrate their pursuit of long-term goals to their beliefs about societal fairness" (p. 149). That is, individuals from low-SES backgrounds might adjust their engagement in behaviors that can promote future socioeconomic success based on their perceptions of the attainability of socioeconomic mobility. These experimental findings are also complemented by at least five cross-sectional and longitudinal studies ${ }^{48,55}$.

\section{Implications of the Framework and Future Directions}

The general conclusions of our unified model provide important policy implications. First, our model and the literature we review imply that disadvantages that are associated with 
poverty are heightened in an environment characterized by high levels of economic inequality. This provides additional support for calls to enact policies designed to reduce inequality ${ }^{56,57}$.

Second, we also note our model's implications for more immediate interventions that could increase the chances of upward mobility among low-SES youth by both changing their perceptions of what is possible for them and increasing their access to mobility-promoting opportunities. The insights presented above imply that it is critical to both expand the opportunities for advancement to low-SES youth and also ensure that these opportunities are presented in such a way as to help them see value in investing their time and energy into pursuing them.

This view is potentially quite promising in that interventions building on these insights need not be prohibitively expensive. For example, mentoring programs (like Big Brothers Big Sisters of America ${ }^{58}$, Arches Transformative Mentoring Program in New York ${ }^{59}$, the College Advising Corps ${ }^{60}$ ) could have high returns at relatively little cost ${ }^{61}$. These initiatives engage volunteers to provide resources, motivation, and strategies for low-SES youth to overcome barriers and achieve work or college goals. They offer students access to relatable figures who understand the barriers they face and thus are able to offer the specific types of resources and advice that they need to navigate the difficult path towards success, which can increase low-SES youth's academic confidence and performance ${ }^{62}$. Our model provides a similar rationale in favor of early-childhood parenting programs and interventions that work with parents to create supportive environments and to help prepare their children to think about their future goals and how school and certain behaviors can help them reach those goals. This rationale is also consistent with evidence that schools that alter the educational system in ways that set high expectations for their students can lead to improved student outcomes ${ }^{63,64}$. These interventions 
all share the feature of directly working to influence youth's perceptions about what they can achieve.

Our model also provides an augmented explanation for why some notable interventions might have been successful at improving the life chances of children who grow up in low-SES households. One category includes programs that focus on the offer of free or heavily subsidized college or community college tuition to high-risk students who complete high school. These include Promise Programs like the Kalamazoo Promise, the Georgia HOPE Scholarship, or the Chicago Star Scholarship. Research has demonstrated that eligible students are relatively more likely to attend and complete post-secondary programs ${ }^{65-67}$. Though generally thought of primarily as tuition subsidy programs, our model suggests that the salient message of the program and the availability of real opportunities might enhance student perceptions of the attainability of future socioeconomic success. It may therefore be the combination of these structural and psychological improvements that ultimately produces positive outcomes.

Our model provides a similar, additional interpretation to the positive findings from the Moving to Opportunity (MTO) experiment, which offered housing vouchers and mobility counseling to families living in public housing to move to low poverty areas ${ }^{68}$. Children who moved experienced increased college attendance and wages, and those who moved at the youngest ages experienced the largest positive effects. The authors attribute these findings to the extended exposure to the greater tangible resources and opportunities in the new environment. Our model augments this interpretation by suggesting that younger children's prolonged exposure to such resources could also have altered their perceptions of what would be possible for them to achieve in their futures.

An important area for future research concerns how other structural and contextual factors that may also contribute to differences in people's beliefs about mobility and opportunity 
(e.g., the availability of successful role models ${ }^{69}$, the extent to which one experiences cultural barriers in school and in the workplace ${ }^{22}$, community support ${ }^{70}$, and others ${ }^{5}$ ) fit within our proposed framework. One possibility is that many such factors may be exacerbated by increased economic inequality. Indeed, as inequality has increased, low-SES communities have had less access to resources have historically provided mobility opportunities ${ }^{34,35}$, and there is emerging evidence that inequality might also alter salient cultural mindsets ${ }^{71}$ and erode community buffers $^{72}$. Exploring these relationships in greater depth will be critical for expanding the scope of our model.

In summary, our model and the related literatures do not imply that low-SES students who avoid positive behaviors do so simply because they hold misguided beliefs about mobility, and that all that is needed is to convince them otherwise. Individuals who believe that mobility is unrealistic likely hold those beliefs because their society has not historically provided viable opportunities for or pathways to mobility for people from their backgrounds ${ }^{4}$. Interventions in this domain should entail real, systemic changes to educational, occupational, and social environments that can provide low-SES youth and young adults with concrete and viable routes to future socioeconomic success and mobility in an increasingly unequal society. 


\section{References}

1. OECD. Income Inequality. OECD Data (2018). Available at:

https://web.archive.org/web/20181004070436/https://data.oecd.org/inequality/incomeinequality.htm. (Accessed: 4th October 2018)

2. Saez, E. Striking it Richer: The Evolution of Top Incomes in the United States. (2016). Available at:

https://web.archive.org/web/20181004070320/https://eml.berkeley.edu/ saez/saezUStopincomes-2015.pdf. (Accessed: 4th October 2018)

3. Stone, C., Trisi, D., Sherman, A. \& Taylor, R. A Guide to Statistics on Historical Trends in Income Inequality. Center on Budget and Policy Priorities (2018). Available at: https://web.archive.org/web/20181004070121/https://www.cbpp.org/research/povertyand-inequality/a-guide-to-statistics-on-historical-trends-in-income-inequality. (Accessed: 4th October 2018)

4. Duncan, G. J. \& Murnane, R. J. Whither Opportunity? Rising Inequality, Schools, and Children's Life Chances. (Russell Sage Foundation, 2011).

5. Markus, H. R. \& Stephens, N. M. Editorial overview: Inequality and social class: The psychological and behavioral consequences of inequality and social class: a theoretical integration. Curr. Opin. Psychol. 18, iv-xii (2017).

6. Lewis, O. The Culture of Poverty. in On Understanding Poverty: Perspectives from the Social Sciences (ed. Moynihan, D. P.) 187-200 (Basic Books, 1969).

7. Wilson, W. J. The Truly Disadvantaged: The Inner City, the Underclass and Public Policy. (University of Chicago Press, 1987).

8. Wilson, W. J. When Work Disappears: The World of the New Urban Poor. (Alfred A. Knopf, 1996). 
9. Markus, H. R. \& Nurius, P. Possible Selves. Am. Psychol. 41, 954 (1986).

10. Oyserman, D. \& Destin, M. Identity-based motivation: Implications for intervention. Couns. Psychol. 38, 1001-1043 (2010).

11. Oyserman, D. Social identity and self-regulation. in Social psychology: Handbook of basic principles (eds. Kruglanski, A. W. \& Higgins, E. T.) 432-453 (Guilford Press, 2007).

12. Oyserman, D. Not just any path: Implications of identity-based motivation for disparities in school outcomes. Econ. Educ. Rev. 33, 179-190 (2013).

13. Roese, N. J. \& Sherman, J. W. Expectancy. in Social Psychology: Handbook of Basic Principles (eds. Kruglanski, A. W. \& Higgins, E. T.) 91-115 (Guilford Press, 2007).

14. Simons, J., Vansteenkiste, M., Lens, W. \& Lacante, M. Placing Motivation and Future Time Perspective Theory in a Temporal Perspective. Educ. Psychol. Rev. 16, 121-139 (2004).

15. Hershfield, H. E. et al. Increasing Saving Behavior Through Age-Progressed Renderings of the Future Self. J. Mark. Res. 48, S23-S37 (2011).

16. Hershfield, H. E., Cohen, T. R. \& Thompson, L. Short horizons and tempting situations: Lack of continuity to our future selves leads to unethical decision making and behavior. Organ. Behav. Hum. Decis. Process. 117, 298-310 (2012).

17. van Gelder, J.-L., Hershfield, H. E. \& Nordgren, L. F. Vividness of the Future Self Predicts Delinquency. Psychol. Sci. 24, 974-980 (2013).

18. Van Gelder, J.-L., Luciano, E. C., Weulen Kranenbarg, M. \& Hershfield, H. E. Friends with my future self: longitudinal vividness intervention reduces delinquency. Criminology 53, 158-179 (2015).

19. Schwarz, N. \& Clore, G. L. Feelings and Phenomenal Experiences. in Social Psychology: Handbook of Basic Principles (eds. Kruglanski, A. W. \& Higgins, E. T.) 385-407 
(Guilford Press, 2007). doi:10.1023/A:1021223113233

20. Markus, H. R. \& Wurf, E. The dynamic self-concept: A social psychological perspective. Annu. Rev. Psychol. 38, 299-337 (1987).

21. McConnell, A. R., Shoda, T. M. \& Skulborstad, H. M. The self as a collection of multiple self-aspects: Structure, development, operation, and implications. Soc. Cogn. 30, 380-395 (2012).

22. Stephens, N. M., Markus, H. R. \& Phillips, L. T. Social Class Culture Cycles: How Three Gateway Contexts Shape Selves and Fuel Inequality. Annu. Rev. Psychol. 65, 611-634 (2014).

23. American Psychological Association. Stress in America: Paying With Our Health. (2015). Available at:

https://web.archive.org/web/20181004070723/https://www.apa.org/news/press/releases/str ess/2014/stress-report.pdf. (Accessed: 4th October 2018)

24. GfK. Money and self-pressure are the leading major causes of stress internationally. (2015). Available at:

https://web.archive.org/web/20181004071338/https://www.gfk.com/fileadmin/user_uploa d/dyna_content/Global/documents/Press_Releases/2015/20151125_PR-study_Majorcauses-of-stress_vfinal.pdf. (Accessed: 4th October 2018)

25. Higher Education Research Institute. The American Freshman: National Norms Fall 2015. (University of California, Los Angeles, 2015).

26. Chetty, R. et al. The fading American dream: Trends in absolute income mobility since 1940. Science (80-. ). 356, 398-406 (2017).

27. Reardon, S. F. \& Bischoff, K. More Unequal and More Separate: Growth in the Residential Segregation of Families by Income. US2010 Project (2011). Available at: 
https://web.archive.org/web/20181004071902/http://cepa.stanford.edu/content/moreunequal-and-more-separate-growth-residential-segregation-families-income-1970-2009. (Accessed: 4th October 2018)

28. Reardon, S. F. The Widening Academic Achievement Gap Between the Rich and the Poor: New Evidence and Possible Explanations. in Whither Opportunity? Rising Inequality and the Uncertain Life Chances of Low-Income Children (eds. Duncan, G. J. \& Murnane, R. J.) 91-115 (Russell Sage Foundation, 2011).

doi:10.3102/00028312042002305

29. Reardon, S. F. \& Bischoff, K. Income Inequality and Income Segregation. Am. J. Sociol. 116, 1092-1153 (2011).

30. Owens, A., Reardon, S. F. \& Jencks, C. Income Segregation Between Schools and School Districts. Am. Educ. Res. J. 53, 1159-1197 (2016).

31. Watson, T. Inequality and the Measurement of Residential Segregation by Income in American Neighborhoods. Rev. Income Wealth 55, 820-844 (2009).

32. Hayes, T. J. Do Citizens Link Attitudes with Preferences? Economic Inequality and Government Spending in the "New Gilded Age". Soc. Sci. Q. 95, 468-485 (2014).

33. Gilens, M. Affluence and Influence: Economic Inequality and Political Power in America. (Princeton University Press, 2012).

34. Bailey, M. J. \& Dynarski, S. M. Inequality in Postsecondary Education. in Whither Opportunity? Rising Inequality, Schools, and Children's Life Chances (eds. Duncan, G. J. \& Murnane, R. J.) 117-132 (Russell Sage Foundation, 2011).

35. Chetty, R., Friedman, J., Saez, E., Turner, N. \& Yagan, D. Mobility Report Cards: The Role of Colleges in Intergenerational Mobility. NBER Working Paper Series, No. 23618 (2017). doi:10.3386/w23618 
36. Becker, G. S. \& Murphy, K. M. The Upside of Income Inequality. Am. (2007).

37. Becker, G. S. \& Tomes, N. An Equilibrium Theory of the Distribution of Income and Intergenerational Mobility. J. Polit. Econ. 87, 1153-1189 (1979).

38. Solon, G. A Model of Intergenerational Mobility Variation over Time and Place. in Generational Income Mobility in North America and Europe (ed. Corak, M.) 38-47 (Cambridge University Press, 2004).

39. Kearney, M. S. \& Levine, P. B. Income Inequality, Social Mobility, and the Decision to Drop Out of High School. Brookings Pap. Econ. Act. 333-396 (2016). doi:10.1353/eca.2016.0017

40. Kearney, M. S. \& Levine, P. B. Income Inequality and Early Non-Marital Childbearing. $J$. Hum. Resour. 49, 1-31 (2014).

41. Genicot, G. \& Ray, D. Aspirations and Inequality. Econometrica 85, 489-519 (2017).

42. Sewell Jr., W. H. \& Hauser, R. M. Education, occupation, and earnings: achievement in the early career. (Academic Press, 1975).

43. Akerlof, G. A. \& Kranton, R. E. Economics and Identity. Q. J. Econ. 115, 715-753 (2000).

44. Kraus, M. W., Piff, P. K., Mendoza-Denton, R., Rheinschmidt, M. L. \& Keltner, D. Social class, solipsism, and contextualism: How the rich are different from the poor. Psychol. Rev. 119, 546-572 (2012).

45. Wegner, D. M. \& Gilbert, D. T. Social Psychology: The Science of Human Experience. in The Message Within: The Role of Subjective Experience in Social Cognition and Behavior (eds. Bless, H. \& Forgas, J. P.) 1-9 (Psychology Press, 2000).

46. Payne, B. K., Brown-Iannuzzi, J. L. \& Hannay, J. W. Economic inequality increases risk taking. Proc. Natl. Acad. Sci. 114, 4643-4648 (2017). 
47. Nishi, A., Shirado, H., Rand, D. G. \& Christakis, N. A. Inequality and visibility of wealth in experimental social networks. Nature 526, 426-429 (2015).

48. Browman, A. S., Destin, M., Carswell, K. L. \& Svoboda, R. C. Perceptions of Socioeconomic Mobility Influence Academic Persistence among Low Socioeconomic Status Students. J. Exp. Soc. Psychol. 72, 45-52 (2017).

49. Day, M. V. \& Fiske, S. T. Movin' on Up? How Perceptions of Social Mobility Affect Our Willingness to Defend the System. Soc. Psychol. Personal. Sci. 8, 267-274 (2017).

50. Shariff, A. F., Wiwad, D. \& Aknin, L. B. Income Mobility Breeds Tolerance for Income Inequality. Perspect. Psychol. Sci. 11, 373-380 (2016).

51. McCall, L., Burk, D., Laperrière, M. \& Richeson, J. A. Exposure to rising inequality shapes Americans' opportunity beliefs and policy support. Proc. Natl. Acad. Sci. 114, 9593-9598 (2017).

52. Davidai, S. Why do Americans believe in economic mobility? Economic inequality, external attributions of wealth and poverty, and the belief in economic mobility. $J$. Exp. Soc. Psychol. 79, 138-148 (2018).

53. Côté, S., House, J. \& Willer, R. High economic inequality leads higher-income individuals to be less generous. Proc. Natl. Acad. Sci. 112, 15838-15843 (2015).

54. Davidai, S. \& Gilovich, T. Building a More Mobile America-One Income Quintile at a Time. Perspect. Psychol. Sci. 10, 60-71 (2015).

55. Laurin, K., Fitzsimons, G. M. \& Kay, A. C. Social disadvantage and the self-regulatory function of justice beliefs. J. Pers. Soc. Psychol. 100, 149-171 (2011).

56. Wilkinson, R. G. \& Pickett, K. E. The Spirit Level: Why Equality is Better for Everyone. (Bloomsbury Press, 2009).

57. United Nations. Goal 10: Reduce inequality within and among countries. (2015). 
Available at:

https://web.archive.org/web/20181002223106/https://www.un.org/sustainabledevelopmen t/inequality/. (Accessed: 4th October 2018)

58. Herrera, C., Grossman, J. B., Kauh, T. J. \& McMaken, J. Mentoring in Schools: An Impact Study of Big Brothers Big Sisters School-Based Mentoring. Child Dev. 82, 346$361(2011)$

59. Lynch, M., Astone, N. M., Collazos, J., Lipman, M. \& Esthappan, S. Arches Transformative Mentoring Program: An Implementation and Impact Evaluation in New York City. The Urban Institute (2018). Available at:

https://web.archive.org/web/20181004072426/https://www.urban.org/sites/default/files/pu blication/96601/arches_transformative_mentoring_program.pdf. (Accessed: 4th October 2018)

60. College Advising Corps. Our Results. (2018). Available at: https://web.archive.org/web/20181004073547/https://advisingcorps.org/our-impact/ourresults/. (Accessed: 4th October 2018)

61. Levine, P. B. Designing Effective Mentoring Programs for Disadvantaged Youth. Brookings Institution (2014). Available at:

https://web.archive.org/web/20181004072843/https://www.brookings.edu/wpcontent/uploads/2016/06/mentor_disadvantaged_youth_levine.pdf. (Accessed: 4th October 2018)

62. Stephens, N. M., Hamedani, M. G. \& Destin, M. Closing the Social-Class Achievement Gap: A Difference-Education Intervention Improves First-Generation Students’ Academic Performance and All Students' College Transition. Psychol. Sci. 25, 943-953 (2014).

63. Dobbie, W. \& Fryer, R. G. Getting beneath the veil of effective schools: Evidence from 
New York City. Am. Econ. J. Appl. Econ. 5, 28-60 (2013).

64. Yeager, D. S. et al. Breaking the cycle of mistrust: Wise interventions to provide critical feedback across the racial divide. J. Exp. Psychol. Gen. 143, 804-824 (2014).

65. Bartik, T. J., Hershbein, B. \& Lachowska, M. The Effects of the Kalamazoo Promise Scholarship on College Enrollment, Persistence, and Completion. W.E. Upjohn Inst. Employ. Res. 15-229, (2017).

66. Cornwell, C., Mustard, D. B. \& Sridhar, D. J. The Enrollment Effects of Merit-Based Financial Aid: Evidence from Georgia’s HOPE Program. J. Labor Econ. 24, 761-786 (2006).

67. Office of the Mayor of the City of Chicago. City Colleges' Star Scholars Thrive in Second Year with a 20 Percent Increase in Enrollment, and Overall Higher Retention Rates and GPA than their Peers. (2016). Available at:

https://web.archive.org/web/20180905221917/https://www.cityofchicago.org/city/en/depts /mayor/press_room/press_releases/2016/october/Star-Scholars-Thrive.html. (Accessed: 4th October 2018)

68. Chetty, R., Hendren, N. \& Katz, L. F. The Effects of Exposure to Better Neighborhoods on Children: New Evidence from the Moving to Opportunity Experiment. Am. Econ. Rev. 106, 855-902 (2016).

69. Roderick, M. What's happening to the boys? Early high school experiences and school outcomes among African American male adolescents in Chicago. Urban Educ. 38, 538607 (2003).

70. Jachimowicz, J. M., Chafik, S., Munrat, S., Prabhu, J. C. \& Weber, E. U. Community trust reduces myopic decisions of low-income individuals. Proc. Natl. Acad. Sci. 114, 54015406 (2017). 
71. Sánchez-Rodríguez, Á., Willis, G. B. \& Rodríguez-Bailón, R. Economic and social distance: Perceived income inequality negatively predicts an interdependent selfconstrual. Int. J. Psychol. (2017). doi:10.1002/ijop.12437

72. Jachimowicz, J. M., Szaszi, B., Lukas, M., Prabhu, J. \& Weber, E. U. The Rising Tide Sinks the Smallest Boats: Why Higher Economic Inequality Intensifies the Poor's Financial Hardship. in Behavioral Decision Research in Management Conference (2018). 